Int. J. Electrochem. Sci., 14 (2019) 8110 - 8120

International Journal of

ELECTROCHEMICAL

SCIENCE

www.electrochemsci.org

\title{
Electrochemical Oxidation Combined with Adsorption: A Novel Route for Low Concentration Organic Wastewater Treatment
}

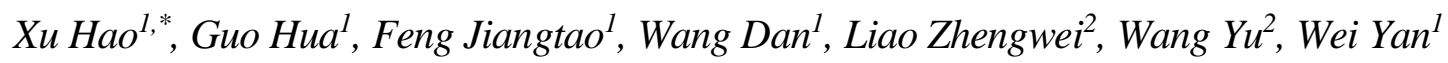 \\ ${ }^{1}$ Department of Environmental Science and Engineering, Xi'an Jiaotong University, Xi'an, 710049, \\ China \\ ${ }^{2}$ Water Affair Science and Technology Research Institute, Shaanxi Water Affair Group, Xi'an, 710021, \\ China \\ *E-mail: xuhao@xjtu.edu.cn
}

doi: $10.20964 / 2019.08 .10$

Received: 8 April 2019 / Accepted: 27 May 2019 / Published: 30 June 2019

Electrochemical oxidation treatment is an efficient method for the mineralization of bio-refractory organics, but not an economic method for its high energy consumption. The results of electrochemical degradation of Acid Red $\mathrm{G}$ in aqueous solution showed that high organic concentration was beneficial for reducing the average energy consumption. Adsorption method has good enrichment effect on low concentration organic wastewater, but it has no degradation ability. In order to overcome the weakness of these two methods, a novel route which use the adsorption method as the pretreatment method for electrocatalytic treatment, was proposed for resolving the high energy consumption issue, especially for the low concentration organic wastewater. The results of by using the Acid Red G, Acid Red 6B and Methyl orange as the turget indicated that the combined process would be a good alternative for the organic wastewater treatment, especially when the organic concentration was low. After electrochemical treatment, the biotoxicity of the concentrated solution is reduced and the biodegradability is improved. These indicated that the treated solution could be returned to the biochemical treatment system and be further treated by the biochemical method.

Keywords: electrochemical oxidation treatment; adsorption; energy consumption; combined process

\section{FULL TEXT}

(C) 2019 The Authors. Published by ESG (www.electrochemsci.org). This article is an open access article distributed under the terms and conditions of the Creative Commons Attribution license (http://creativecommons.org/licenses/by/4.0/). 